\title{
The role of tetracyclines in the treatment of non-specific urethritis
}

\author{
B. A. EVANS \\ From the Department of Genito-Urinary Medicine, West London Hospital, London
}

SUMMARY An assessment of the clinical findings and treatment in 400 patients with non-specific urethritis (NSU) is reported, and the effect of treating their contacts is analysed. Three tetracyclines were compared in a randomised trial which showed that low-dose oxytetracycline (250 mg twice a day) was as effective as preparations formulated specifically for twice daily administration (triple tetracycline and sustained-release tetracycline hydrochloride). The question of multiple aetiology was explored by testing statistically whether various clinical features such as age, incubation period, severity of symptoms, and previous infection were related to outcome. No subgrouping of the condition could be found. Clinical relapse proved to be independent of empirical treatment of asymptomatic contacts, which therefore appeared not to confer any benefit on either partner. It is suggested that the infective aspect of NSU is readily controlled, and that other factors, probably psychological, determine relapse.

\section{Introduction}

Tetracyclines have consistently proved the most effective treatment for non-specific urethritis (King, 1973). Nevertheless, there is considerable disagreement with regard to daily dose, duration of treatment, and particular form of tetracycline most effective in curing the condition.

Another controversial aspect of the management of this condition is whether or not known contacts who show no clinical, bacteriological, or cytological abnormality should be treated empirically with a similar course of tetracycline.

This paper reports a randomised trial comparing three tetracyclines (oxytetracycline, triple tetracycline, and sustained-release tetracycline), each prescribed as one tablet twice daily for seven days. It also examines various factors, including treatment of contacts, which may be related to resolution of the condition.

\section{Material and methods}

The trial was undertaken on 400 patients seen in the Department of Genito-Urinary Medicine, West

Address for reprints: Dr B. A. Evans, Department of Genito-Urinary Medicine, West London Hospital, Hammersmith Road, London W6 $7 D Q$

Received for publication 6 July 1976
London Hospital, between April and September 1975. Patients who had been treated for NSU during the previous 12 months were excluded, as was anyone who had been given antibiotics during the past three months. Diagnosis of, or contact with, any other sexually transmissible disease also precluded acceptance for the trial, and so did any suggestion of tetracycline allergy.

Patients were allocated one of three treatments according to a prepared randomisation chart and the treatment given remained unknown to the prescriber until after the outcome had been assessed. These regimens were oxytetracycline, $250 \mathrm{mg}$ twice daily, triple tetracycline (Deteclo) 1 tablet twice daily, and sustained-release tetracycline (Sustamycin) $1250 \mathrm{mg}$ capsule twice daily, each continued for seven days. Attendance for assessment was requested at one week, two weeks, and four weeks after the start of treatment.

Smears of urethral exudate were examined using a $\times 100$ oil immersion objective lens and the diagnosis was based on the presence of more than 10 polymorphonuclear leucocytes (PMN) in five microscope fields. Additional investigations consisted of culture for Neisseria gonorrhoeae and macroscopical examination of the urine for urethral threads. Patients were regarded as cured if their urethral smear was normal and they had held their urine for more than two hours. The urine was routinely examined for threads at each follow-up attendance and a clear 
urethral flush of urine provided equally good evidence of resolution. No patient was assessed for the trial until three months from starting treatment, thus ensuring that late relapses were not omitted from the results. The statistical significance of the results was assessed using the $\chi^{2}$ test.

All patients were asked to invite their recent sexual contacts to attend for examination, and a contact slip was provided to verify the reason for their attendance.

\section{Results}

The ages of the 400 patients admitted to the trial ranged between 16 and 59 years (mean 28 years); $22(5 \cdot 5 \%)$ were homosexual. Forty-eight patients $(12 \%)$ had to be taken out of the trial for a wide variety of reasons; of these 29 required treatment for other conditions, including gonorrhoea (three cases), trichomoniasis (two cases) and contact with trichomoniasis (five cases), genital warts (eight cases), and treponemal infection (five cases, two of which were early syphilis), and in most of the remainder the criteria of the protocol had not been fulfilled. Altogether 133 patients $(33 \%)$ defaulted before two weeks' observation had been completed, leaving 219 patients who could be adequately assessed regarding the outcome of their treatment. These results are summarised in Table 1.

Table 1 Outcome of trial

\begin{tabular}{lllllll}
\hline Outcome & \multicolumn{2}{l}{ Drug group } & & \multicolumn{2}{c}{ Total patients } \\
\cline { 2 - 4 } & $\begin{array}{l}\text { Oxy- } \\
\text { tetracycline }\end{array}$ & $\begin{array}{l}\text { Triple } \\
\text { tetracycline }\end{array}$ & $\begin{array}{l}\text { Sustained } \\
\text { release } \\
\text { tetracycline }\end{array}$ & & No. & $\%$ \\
\hline Removed & 18 & 11 & 19 & & 48 & 12 \\
Defaulted & 47 & 41 & 45 & & 133 & 33 \\
Relapsed & 22 & 29 & 25 & & 76 & 19 \\
Cured & 47 & 51 & 45 & & 143 & 36 \\
Total & 134 & 132 & 134 & & 400 & \\
\hline
\end{tabular}

There was no significant difference between the results of treatment with the three tetracyclines no matter which procedure was used to evaluate the outcome $(P=0.7)$. In fact, low dose oxytetracycline produced marginally the best results: only $22(19 \%)$ of those patients who received this drug required further treatment during the next three months, compared with 25 patients $(22 \%)$ of those who received sustained-release tetracycline and $29(24 \%)$ of those who received triple tetracycline. There was also no difference between the results with the three tetracyclines in respect of whether the relapse was early (two to four weeks from treatment) or late (one to three months from treatment). This is shown in Table 2.
Table 2 Relapse of NSU

\begin{tabular}{lllll}
\hline Relapse & Drug group & & $\begin{array}{l}\text { Total } \\
\text { patients }\end{array}$ \\
\cline { 2 - 4 } & $\begin{array}{l}\text { Oxy- } \\
\text { tetracycline }\end{array}$ & $\begin{array}{l}\text { Triple } \\
\text { tetracycline }\end{array}$ & $\begin{array}{l}\text { Sustained- } \\
\text { release } \\
\text { tetracycline }\end{array}$ & \\
\hline $\begin{array}{l}\text { Early } \\
(2-4 \text { weeks) } \\
\text { Late } \\
(1-3 \text { months) }\end{array}$ & 16 & 22 & 17 & 55 \\
Total & 22 & 7 & 8 & 21 \\
\hline
\end{tabular}

Patients who had had a contact treated were grouped according to the outcome of their own response to treatment (Table 3). This shows no significant difference between the relapse and no relapse groups $(P=0 \cdot 6)$. However, there was a marked difference in admitted re-exposure between those patients relapsing within a month of treatment $(14.5 \%)$ and those who relapsed later $(90 \%)$; subsequent sexual intercourse was not recorded in the relapse-free group.

Table 3 Treatment of contacts of patients with NSU

\begin{tabular}{|c|c|c|c|c|}
\hline \multirow[t]{2}{*}{ Patients with NSU } & \multicolumn{2}{|l|}{ Relapse } & \multirow[t]{2}{*}{ No relapse } & \multirow[t]{2}{*}{ Total } \\
\hline & Early & Late & & \\
\hline $\begin{array}{l}\text { Total } \\
\text { No. with treated }\end{array}$ & 55 & 21 & 143 & 219 \\
\hline $\begin{array}{l}\text { contact } \\
\text { Delay before } \\
\text { treatment (days) }\end{array}$ & $17(30 \%)$ & $6(29 \%)$ & $33(23 \%)$ & 56 \\
\hline $\begin{array}{l}\text { Mean } \\
\text { Range } \\
\text { History of re-exposure }\end{array}$ & $\begin{array}{l}4 \cdot 0 \\
0-12 \\
8(15 \%)\end{array}$ & $\begin{array}{l}7 \cdot 1 \\
0-28 \\
19(90 \%)\end{array}$ & $\begin{array}{c}4 \cdot 6 \\
0-24 \\
\text { Not recorded }\end{array}$ & \\
\hline
\end{tabular}

Other factors which might have influenced the outcome of treatment are recorded in Table 4. No significant difference emerged in respect of age, duration of symptoms, interval since sexual intercourse, or microscopical assessment of urethral discharge between the three treatment groups. A history of NSU did not appear more commonly in

Table 4 Other clinical findings with possible influence on outcome

\begin{tabular}{|c|c|c|c|c|}
\hline \multirow[t]{2}{*}{ Clinical findings } & \multicolumn{2}{|c|}{ Relapse } & \multirow[t]{2}{*}{ No relapse } & \multirow[t]{2}{*}{$\mathbf{P}$} \\
\hline & Early & Late & & \\
\hline $\begin{array}{l}\text { Age (mean years) } \\
\text { Duration of symptoms }\end{array}$ & $27 \cdot 7$ & $27 \cdot 7$ & $27 \cdot 6$ & 0.99 \\
\hline $\begin{array}{l}\text { (mean days) } \\
\text { Interval since sexual intercourse }\end{array}$ & $7 \cdot 5$ & $14 \cdot 2$ & 9.5 & 0.3 \\
\hline $\begin{array}{l}\text { (mean days) } \\
\text { Microscopical pus in discharge }\end{array}$ & $11 \cdot 1$ & $15 \cdot 0$ & $12 \cdot 7$ & 0.99 \\
\hline $\begin{array}{l}\text { (mean +'s)* } \\
\text { Previous NSU (total patients) }\end{array}$ & $20^{2 \cdot 2}$ & $\begin{array}{l}1 \cdot 8 \\
6\end{array}$ & $34^{1 \cdot 7}$ & $\begin{array}{l}0.96 \\
0.3\end{array}$ \\
\hline
\end{tabular}

*+10-20 PMN/HPF : + 20-40 PMN/HPF $:++>40$ PMN/HPF. 
the relapsing patients $(P=0.3)$, although no patient who had had NSU during the previous year had been admitted to the trial.

It had been planned that a urethral smear at four weeks should be the test of cure, but in practice only about a quarter of patients actually had this test (Table 5). This deficiency renders the quotation of a cure rate unacceptable, particularly as five patients who were found to have relapsed were asymptomatic. Therefore the figures have been given for re-treatment during a three-month period, a concept used by Willcox et al. (1975), which permits comparison with a large bibliography of previous trials.

Table 5 Tests of cure

\begin{tabular}{lllll}
\hline Test of cure & \multicolumn{2}{c}{ Drug group } & & $\begin{array}{l}\text { Total } \\
\text { patients }\end{array}$ \\
\cline { 2 - 4 } & $\begin{array}{l}\text { Oxy- } \\
\text { tetracycline }\end{array}$ & $\begin{array}{l}\text { Triple } \\
\text { tetracycline }\end{array}$ & $\begin{array}{l}\text { Sustained- } \\
\text { release } \\
\text { tetracycline }\end{array}$ & \\
\hline $\begin{array}{l}\text { Urethral smear } \\
\begin{array}{l}\text { Urethral flush } \\
\text { only }\end{array}\end{array}$ & 32 & 32 & 34 & 98 \\
\begin{tabular}{l} 
Total \\
\hline
\end{tabular} & 51 & 22 & 17 & 58 \\
\hline
\end{tabular}

The Figure shows the diagnosis of relapse against time from treatment and illustrates that this continues right to the end of the arbitrary three-month period, which ought therefore to be extended.

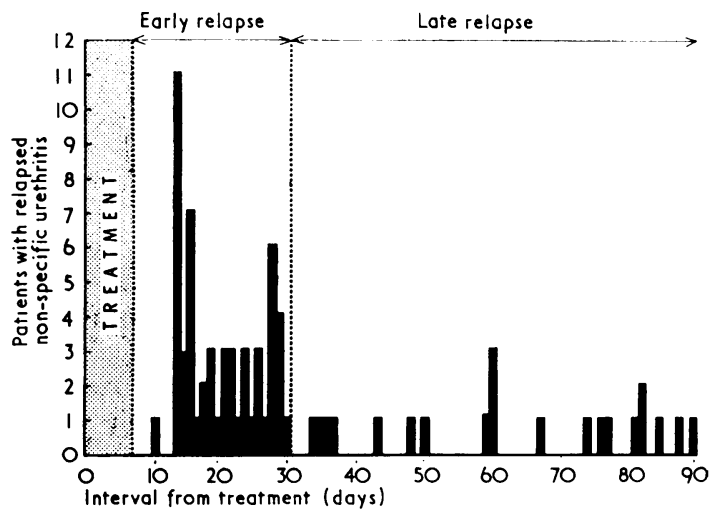

Figure Interval between initial treatment of NSU and diagnosis of relapse.

\section{Discussion}

Treatment of NSU with a single course of a tetracycline was unsuccessful in 10 to $20 \%$ of patients observed during a period of three months (Willcox et al., 1975). Prolonged courses lasting up to three weeks have been advocated, but the results reported fall within the figures quoted above (John, 1971; Bhattacharyya and Morton, 1973). The current trial is the first to report the effect of low-dose oxytetracycline $(250 \mathrm{mg}$ twice daily). That these results should be comparable with standard and even prolonged chemotherapy, suggests that NSU is a mild infection easily cured, a view supported by a placebo cure rate of $34 \%$ (Fowler, 1970). Why then is there so commonly a relapse in 10 to $20 \%$ of cases, independent of the amount of tetracyclines given?

Treatment of contacts on an empirical basis is widely accepted as necessary, but this has not been validated statistically, and no evidence has appeared to support treatment of contacts (Rosedale, 1959). Figures from this trial show that only $26 \%$ of patients had a contact treated, and that this did not relate significantly to the patients who relapsed or to those who did not $(P==0.6)$. Clinical findings are strikingly normal in contacts of NSU, and the incidence of trichomoniasis and candidosis is lower than in a clinic population overall (unpublished observations). Perhaps the cause of NSU is spontaneously eliminated from the female genital tract. Another possibility is that some men acquire immunity during the course of clinical infection, or perhaps develop tolerance to the organism subclinically.

There also appears to be no way of distinguishing separate clinical groups of patients in relation to their treatment responses. Neither the duration of symptoms nor the purulence of the discharge, which provide indices of the severity of the urethritis, was related to outcome. The interval since sexual intercourse was used as a parameter for incubation, but this also failed to identify possible subgroups of NSU.

The finding of a past history might suggest predisposition to NSU. Cases treated within the previous year were excluded in order to minimise biased response from those who may then have received oxytetracycline in larger dosage. Nevertheless, patients with a more distant history of NSU were proportionately distributed between the relapse and no relapse groups.

Additional evidence against re-infection lies in the denial of further intercourse by $85 \%$ of patients relapsing in the first month. This finding, taken in conjunction with the recent report that Chlamydia trachomatis was not isolated from any patient with relapsed NSU within six weeks of initial treatment (Handsfield et al., 1976), provides another indication that relapse may not be infective. In complete contrast, re-exposure was admitted by $90 \%$ of those who relapsed later. Unfortunately, this question was not asked of cured patients, whose behaviour might have been similar. 
It is possible that psychological factors may play a major part in determining relapse; erratic or incomplete compliance with intermittent medication is well known. Excessive and repeated physical examination of the urethra, particularly by the patient, may well maintain a continuous discharge as a result of persistent mucosal irritation, and psychosomatic elements may also come into play. This hypothesis is difficult to test, but a long-term prospective study in this Department using psychometric tests is currently looking at various personality factors, including hypochondriasis, in this connection.

The author wishes to thank Mr James Bennett, SRN, RMN and his colleagues for invaluable help in the conduct of the trial.
References

Bhattacharyya, M. N., and Morton, R. S. (1973). Long-term triple tetracycline ('Deteclo') treatment of non-specific urethritis. British Journal of Venereal Diseases, 49, 521-523.

Fowler, W. (1970). Studies in non-gonococcal urethritis therapy. British Journal of Venereal Diseases, 46, 464-468.

Handsfield, H. H., Alexander, E. R., Pin Wang, S., Pederson, A. H. B., and Holmes, K. K. (1976). Differences in the therapeutic response of chlamydia-positive and chlamydia-negative forms of nongonococcal urethritis. Journal of the American Venereal Disease Association, 2, 5-9.

John, J. (1971). Efficacy of prolonged regimes of oxytetracycline in the treatment of non-gonococcal urethritis. British Journal of Venereal Diseases, 47, 266-268.

King, A. J. (1973). In Price's Textbook of the Practice of Medicine. Edited by R. Bodley-Scott, 11th edition, p. 151. Oxford University Press: London.

Rosedale, N. (1959). Female consorts of men with non-gonococcal urethritis. British Journal of Venereal Diseases, 35, 245-248.

Willcox, R. R., Sparrow, R. W., and Fazluddin, C. M. (1975). Minocycline in the treatment of non-gonococcal urethritis. British Journal of Venereal Diseases, 51, 206-209. 